\title{
Com deficiência, mulher e refugiada: uma tríade omnileticamente interseccional ${ }^{1}$
}

\author{
Disabled, female and refugee: an omniletically intersectional triad
}

Discapacitada, mujer y refugiada: una tríada omnilécticamente interseccional

\section{Mônica Pereira dos Santos}

Professora doutora da Universidade Federal do Rio de Janeiro, Rio de Janeiro, RJ, Brasil

E-mail: monicapes@gmail.com ORCID: https://orcid.org/0000-0002-7057-7804

Mylene Cristina Santiago

Professora doutora da Universidade Federal de Juiz de Fora, Juiz de Fora, MG, Brasil

E-mail: mylenesantiago87@gmail.com ORCID: https://orcid.org/0000-0003-2769-8421

Recebido em 13 de setembro de 2021

Aprovado em 06 de dezembro de 2021

Publicado em 27 de dezembro de 2021

\section{RESUMO}

Sabe-se que dentre os grupos minoritários, o das pessoas com deficiência é o mais numeroso no mundo (ONU, 2016). Entre a população de refugiados, cerca de 7 a 10\% são pessoas com deficiência (NOGUEIRA, 2017). No Brasil, a média de mulheres pleiteantes à condição de refugiadas é relativamente próxima à de homens: 44,75 e 55,23\%, respectivamente (SILVA, G. J. et al, 2020). Estes dados garantem às pessoas com deficiência o status de um forte marcador identitário, assim como lhes conferem alto status de representatividade perante outras minorias, os quais, em si mesmos, seriam motivos suficientes para a garantia de políticas públicas favoráveis à inclusão de quaisquer pessoas cujo marcador se iniciasse pela deficiência em todos os níveis educacionais, inclusive o Superior. Contudo, não é assim que a realidade concreta se mostra. Estes números pioram quando as pessoas com deficiência a quem nos referimos são mulheres refugiadas. Com o objetivo de ampliar as discussões que envolvem as pessoas com deficiência para além do marcador "deficiência" em si, este artigo pretende discutir as temáticas cruzadas (interseccionadas) de mulheres refugiadas e com deficiência, revelando e desvelando o interjogo entre culturas, políticas e práticas dialética e complexamente presentes neste quadro interseccional. Trata-se de um estudo exploratório tendo por referencial analítico a perspectiva Omnilética de Santos (2013) e o conceito de interseccionalidade. As perguntas que nos inspiram são: Como a ciência tem tratado esses assuntos? Têm eles sido estudados interseccionalmente? Qual a produção científica já produzida neste sentido? Nossas conclusões apontam para a confirmação de nossas suspeitas no sentido da necessidade de investimento em produção de conhecimento em uma perspectiva interseccional acerca de mulheres refugiadas com deficiência, tendo em vista subsidiar o desenvolvimento e a implementação de políticas públicas que lhes assegurem o direito de uma vida minimamente digna. 
http://dx.doi.org/10.5902/1984686X67656

Palavras-chave: Perspectiva omnilética de inclusão; Interseccionalidade; Mulheres com deficiência, Refugiadas.

\section{ABSTRACT}

Among minority groups, people with disabilities are the most numerous in the world (ONUNEWS, 2016). Among the refugee population, about 7 to $10 \%$ have disabilities (NOGUEIRA, 2019). In Brazil, the average number of women pleading for refugee status is relatively close to men: 44.75 and $55.23 \%$, respectively (SILVA, G. J. et al, 2020). These data guarantee the deficiency the status of a strong identity marker, as well as give them high representation before other minorities, which, in themselves, would be sufficient reasons for ensuring public policies favorable to the inclusion of any people whose marker was started by disability at all educational levels, including the Superior. However, this is not how reality is shown. This situation worsens when the people with disabilities we refer to, are women and refugees. With a view to broadening the discussions about disability beyond the "disability" marker per se, we aim to discuss the interseccional theme of female refugees with disabilities, revealing and unveiling the interplay between cultures, policies and practices, dialectical and complexly present in an intersectional framework. This is an exploratory study based on the analytical reference of the Omnilética perspective of Santos (2013) and the concept of intersectionality. The questions that inspire us are: Has science dealt with these issues intersectionally? What scientific production has already been produced in this sense? Our conclusions point to the need for knowledge production in an intersectional perspective about refugee women with disabilities in order to support the development and implementation of public policies that guarantee them the right to a minimally dignified life.

Keywords: Omnilectical perspective of inclusion; Intersectionality; Disabled women; Refugees.

\section{RESUMEN}

Entre los grupos minoritarios, las personas con discapacidad son las más numerosas del mundo (ONUNEWS, 2016). Entre la población refugiada, alrededor del 7 al $10 \%$ tiene discapacidades (NOGUEIRA, 2019). En Brasil, el número promedio de mujeres que solicitan el estatus de refugiado es relativamente cercano a los hombres: 44,75 y $55,23 \%$, respectivamente (SILVA, G. J. et al, 2020). Estos datos garantizan a la deficiencia el estatus de un marcador de identidad fuerte, así como les dan una alta representación ante otras minorías, lo que, en sí mismo, sería razón suficiente para asegurar políticas públicas favorables a la inclusión de cualquier persona cuyo marcador se inició por discapacidad en todos los niveles educativos, incluido el Superior. Sin embargo, no es así como se muestra la realidad. Esta situación se agrava cuando las personas con discapacidad a las que nos referimos son mujeres y refugiadas. Con el objetivo de ampliar las discusiones que involucran a personas con discapacidad más allá del marcador de "discapacidad" en sí, nuestra intención es discutir los temas intersectantes de las mujeres refugiadas y discapacitadas, revelando la interacción entre culturas, políticas y prácticas, dialécticas y 
complejamente presentes en este marco interseccional. Se trata de un estudio exploratorio basado en la referencia analítica de la perspectiva Omnilética de Santos (2013) y el concepto de interseccionalidad. Las preguntas que nos inspiran son: ¿La ciencia ha tratado estos temas de manera interseccional? ¿Qué producción científica se ha producido ya en este sentido? Nuestras conclusiones apuntan a la necesidad de la producción de conocimiento en una perspectiva interseccional sobre las mujeres refugiadas con discapacidad para apoyar el desarrollo e implementación de políticas públicas que le garanticen el derecho a una vida mínimamente digna.

Palabras clave: Perspectiva omnilética de inclusión; Interseccionalidad; Mujeres con discapacidad, Refugiadas.

\section{Introdução}

Deficiencidade, mulheridade e refugiaridade. Três palavras que acabamos de criar para tentar definir três temas que nos impactam pelos desafios que apresentam a todos nós naquilo que nos une como espécie. Que nos instigam pelo pouco que ainda acumulamos de conhecimento científico no contexto brasileiro. Que nos impressionam pelo exemplo em que nos inspiramos daquelas que, identificadas dentro dessa tríade de rótulos que Ihes são impostos, exercem, cotidianamente, a coragem e ousadia de vencerem os mais excruciantes obstáculos a que são submetidas pelo simples fato de existirem, de serem.

Em entrevista dada em 2016 ao ONUNews (ONU, 2016), o Diretor-geral da Organização Internacional do Trabalho (OIT), agência da ONU para o Trabalho, Guy Ryder, afirmou que "as pessoas com deficiência representam o maior grupo de minorias do mundo. Elas correspondem a 15\% da população global, pouco mais de 1 bilhão de pessoas e $80 \%$ delas em idade para trabalhar." Da mesma forma, o documento do Comissariado para Mulheres da ONU (BROWNE, 2017), aponta que cerca de um bilhão de pessoas no mundo experimentam algum tipo de deficiência ao longo da vida e que essa prevalência é $19 \%$ maior para mulheres, quando comparada aos homens (que é de 12\%).

No campo da Educação, desde a promulgação da Declaração Mundial de Educação para todos, em Jomtien, na Tailândia, em 1990 (UNESCO, 1990), e nos seus Relatórios de Acompanhamento e subsequentes Declarações (UNESCO, 2000; 2015), tem ficado cada vez mais claro o quanto mulheres e meninas ainda são excluídas do sistema educacional dos países, mundo afora. Ainda que no Brasil este não seja o caso², quando se pensa no mercado de trabalho, essa exclusão pode ser verificada, com as mulheres ocupando os cargos menos importantes na escala hierárquica do local de trabalho a que pertencem $\mathrm{e}$ 
http://dx.doi.org/10.5902/1984686X67656

sempre, mesmo que em cargos de poder, ganhando menos do que os homens (ELIAS, 2021).

No caso da população de refugiados no mundo, dados do Relatório das Nações Unidas para Refugiados - Tendências Globais (UNHCR, 2020), apontam que 52\% deste grupo é de mulheres. No Brasil, os números não ficam muito atrás, já que a média de mulheres pleiteantes à condição de refugiadas é relativamente próxima à de homens: 44,75 versus 55,23\%, respectivamente (SILVA, G. J. et al, 2020).

Aqui, cabe uma explicação. A distinção entre migração e refúgio remete ao campo legal, na medida em que a conceituação está disposta nos documentos regulamentares das políticas internacionais e na legislação local, de acordo com Prado e Araújo (2019, p, 573), para quem

\begin{abstract}
O refugiado é um migrante que possui estatuto diferenciado, alvo de políticas específicas, que foi forçado a deixar seu país por circunstâncias de ameaça à vida e a ele não pode retornar. A migração ocorre por motivos variados, mas questões econômicas e sociais estão no bojo da decisão de migrar, impulsionada principalmente por condições precárias de vida. Resguardadas as particularidades, ambos dizem respeito ao deslocamento de pessoas que saem do seu local de residência habitual em busca de proteção ou de melhorias das condições de vida, que enfrentam comumente situações extremas no percurso de deslocamento, e precisam se adaptar a um novo território, cultura e construir novas relações. Para além dos contornos conceituais, tratam-se de experiências bastante heterogêneas quando se atenta para as singularidades com as quais se dão os fluxos de indivíduos, famílias e coletividades.
\end{abstract}

Desta maneira, e retornando ao foco de nossa atenção, a condição interseccional de ser mulher (mulheridade), com deficiência (deficiencidade) e refugiada (refugiaridade), em geral, e no Brasil em particular, um país cada vez mais internacionalmente reconhecido por suas facetas machistas/sexistas/misóginas, capacitistas e xenofóbicas, é um enorme desafio. $E$ isso sem contar que não estamos computando raça-etnia e condição social nesse artigo, por pura falta de espaço.

A título de exemplo, ao visitarmos o site da Agência da ONU para Refugiados (ACNUR) no Brasil ${ }^{3}$, nos deparamos com uma proposta que busca oferecer capacitação de mulheres refugiadas e migrantes para ingressarem no mercado de trabalho brasileiro (NOVAES, 2020).

O grupo foco desta ação são mulheres que fugiram da violência e da crise econômica em seu país de origem, a Venezuela, e buscaram proteção e assistência no Brasil. Para além da barreira linguística com o português, as mulheres têm deficiência, fator que amplia 
http://dx.doi.org/10.5902/1984686X67656

os desafios para a inserção no mercado de trabalho. Salientamos que educação e inserção no mercado de trabalho são meios fundamentais para a inclusão de pessoas refugiadas.

Nos depoimentos apresentados no site, vemo-nos diante de histórias de vida com barreiras causadas pela forma preconceituosa com que a sociedade lida com a deficiência e que são agravadas pela crise política e econômica do país de origem. Por outro lado, os relatos revelam desejo de inserção no mercado de trabalho para oferecer condições de existência dignas a si mesmas, aos filhos e outros entes que as acompanham na jornada em abrigos que acolhem pessoas refugiadas e migrantes da Venezuela, em Boa Vista (Roraima).

Pelo exposto, este artigo objetiva ampliar as discussões que envolvem as pessoas com deficiência com as temáticas cruzadas de mulheres refugiadas e com deficiência, operando com a interseccionalidade enquanto conceito que nos permite compreender como as articulações de diferentes categorias identitárias e sociais se imbricam e estruturam a vida de cada sujeito e/ou grupo, ampliando situações de desigualdades, de violações de direitos e desumanização, revelando-a e desvelando-a omnileticamente, ou seja, compreendendo o interjogo entre culturas, políticas e práticas dialética e complexamente presentes neste quadro interseccional.

\section{Sobre a Omnilética}

A perspectiva Omnilética foi cunhada por Santos (2012) para caracterizar uma perspectiva de análise que the permitisse "compreender os fenômenos sociais em sua integralidade visível e em sua potencialidade invisível, mas não necessariamente ausente, seja por estar apenas oculta, seja por existir, ainda, apenas potencialmente" (p. 1223). Para uso da perspectiva que hoje a autora considera como ontoepistemológica, porque implica tanto uma reflexão contínua e crítica sobre a implicação daquele que analisa quanto daquilo ou daquele que é analisado, ela afirma ser necessário admitir a realidade em termos de cinco dimensões por meio das quais se manifesta: cultural, política, prática, dialética e complexa.

Para as dimensões de culturas, políticas e práticas, a autora se baseia em Booth e Ainscow (2011), de cujo primeiro autor é parceira de trabalho há muitos anos e com quem contribuiu para o desenvolvimento do Index para Inclusão, material práxico construído pelos autores ingleses e que traduziu para o português, e que gerou uma rede internacional da qual é representante no Brasil (International Index for Inclusion Network). Por intermédio do 
http://dx.doi.org/10.5902/1984686X67656

Index, os autores propõem as referidas três dimensões, que significam a construção e edificação de valores para uma comunidade de inclusão (culturas); os arranjos administrativos e organizacionais em apoio a ações institucionais orientadas por princípios de inclusão (políticas); e as ações e atos cotidianos de cada ator social na construção de um mundo orientado por princípios e organizado para a inclusão (práticas).

Para a dimensão dialética, a autora recorre a Lukács, particularmente em suas discussões acerca da noção de totalidade, quando afirma que:

A concepção dialético-materialista da totalidade significa, primeiro, a unidade concreta de contradições que interagem (...); segundo, a relatividade sistemática de toda a totalidade tanto no sentido ascendente quanto no descendente (o que significa que toda a totalidade é feita de totalidades a ela subordinadas, e também que a totalidade em questão é, ao mesmo tempo, sobredeterminada por totalidades de complexidade superior...) e, terceiro, a relatividade histórica de toda totalidade, ou seja, que o caráter de totalidade de toda totalidade é mutável, desintegrável e limitado a um período histórico concreto e determinado. (LUKÁCS, 1975, p.12)

Em outras palavras, trata-se de uma visão de totalidade como elemento central do próprio movimento dialético que, na omnilética, não representa, unicamente, a superação de contradições; a mesma mutabilidade, desintegrabilidade e limitação históricas concretas das totalidades em jogo podem bem produzir, ao invés de sínteses, teses e antíteses concorrentes e complementares, ao mesmo e um só tempo, sobre e em dada realidade. $\mathrm{Na}$ omnilética, essa realidade - que não deixa de ser uma totalidade - é sempre cultural, política, prática e complexa, além de dialética.

Ao pensar a totalidade neste jogo de mutabilidade histórica e concretamente situadas a partir de Lukács, Santos, agora em sua obra de 2013, aprofundando a ideia lukacsiana do jogo também dialético entre diferentes totalidades como "complexos de complexos", chega a Morin (2000) e seu conceito de complexidade.

Morin discute a complexidade - ou, mais precisamente, o que denomina de pensamento complexo -, como todo ato reflexivo que se oponha a uma análise simplificadora da(s) realidade(s), o que implica nos colocarmos, continuamente, em posição de combate ao pensamento - a cuja tradição estamos, ainda, muito arraigados -, que separa, que fragmenta e reduz o sentido do real. Ao operarmos na fragmentação, ao construirmos conhecimento fundamentado nos preceitos da ciência moderna (a qual, "no intuito de conhecer e estabelecer a verdade sobre o mundo físico, e até mesmo social, consagra alguns princípios como: a ordem, a separação, a redução e a validade absoluta da lógica clássica" - MARTINAZZO e DRESK, 2013, p. 50) e praticarmos esta separação, 
http://dx.doi.org/10.5902/1984686X67656

perdemos a visão destes conhecimentos em relação à realidade, ao seu contexto, como uma totalidade, caindo na ilusão de um conhecimento "verdadeiro", único e universal. Isso, por sua vez, pode cerrar as portas para o inesperado, a invenção, a criação e a compreensão da multiplicidade de olhares e explicações possíveis sobre os fenômenos da vida. Pelo pensamento complexo, por outro lado, somos capazes de reconhecer as incertezas que conhecer e produzir conhecimento trazem em seu bojo. Nas palavras de Morin, compreender a incerteza do real é "saber que há algo possível ainda invisível no real" (MORIN e Le MOIGNE, 2000, p. 85).

Na perspectiva omnilética, portanto, no que tange ao pensamento complexo, tomamos de empréstimo, em especial, da teoria de Morin, a ideia de incerteza e, parafraseando o que o próprio Morin dizia, caminhamos por mares de incerteza entre arquipélagos de certeza. Em termos práxicos, portanto, a perspectiva omnilética é definida por Santos (2013, p.23) como:

(...) um modo de explicar/conceber e ser ao mesmo tempo. Um conceito, portanto, de caráter tanto reflexivo e contemplativo quanto aplicativo às nossas práticas, ao nosso modo de ser. O termo omnilética é composto de três elementos morfológicos: o prefixo latino omni (tudo, todo), o radical grego lektos (variedades, diferença linguística, mas aqui enfatizando especialmente a variedade e a diferença) e o sufixo grego ico (concernente a). Resumidamente, omnilética significa uma maneira totalizante de compreender as diferenças como partes de um quadro maior, caracterizado por suas dimensões culturais, políticas e práticas em uma relação ao mesmo tempo complexa e dialética.

\section{Método}

Metodologicamente, trata-se de um estudo exploratório tendo por referencial analítico a perspectiva Omnilética de Santos $(2012,2013)$ e o conceito de interseccionalidade.

Intrigadas e indignadas com o que temos estudado (em separado) e refletido (interseccionadamente) sobre estes três assuntos, optamos por aprofundar nossas buscas e reflexões acerca deles neste artigo com este pequeno estudo exploratório. Queríamos, ao menos, saber se a literatura científica vem discutindo esses três aspectos de forma interseccional (o que achávamos que não), e se sim, de que modo, em que direções. Optamos, então, pelo delineamento do estudo exploratório, que para Babbie,

Estudos exploratórios são tipicamente feitos por três motivos: (1) simplesmente para satisfazer a curiosidade do pesquisador e seu desejo de uma melhor compreensão, (2) para testar o quão factível seria o desenvolvimento de um estudo mais aprofundado e (3) para desenvolver os métodos a serem empregados em um estudo mais aprofundado (1986, p. 68).

(Tradução livre) 
http://dx.doi.org/10.5902/1984686X67656

Em nosso caso, os três motivos nos moviam. Assim, a partir de uma revisão de literatura com foco na temática mulheres refugiadas com deficiência, teceremos, aqui, nossa análise omnilética sobre as leituras que levantamos tendo a questão dessa interseccionalidade triádica como pano de fundo. Limitamo-nos à busca de produções mais recentes (2016-2021), tendo em vista nosso pequeno espaço para discussão, mas mantendo a intenção de cobrir os últimos 5 anos em termos de revisão de literatura científica em Educação a respeito do cruzamento destas três temáticas.

Os descritores que utilizamos foram gênero, deficiência, refugiados (e os seguintes afins: menina(s), mulher(es), garota(s), femin), deficiência (e os seguintes afins: defic, PcD, portador(es), deficiente(s), pessoa com) e refugiados (com a variação refúgio).

Consultamos duas fontes dentro do site da Associação Nacional de Pós-graduação e Pesquisa em Educação (ANPEd): a Revista Brasileira de Educação e as publicações de seus GTs 15 (Educação Especial), GT 21 (Educação e Relações Étnico-Raciais) e GT 23 (Gênero, Sexualidade e Educação) nas reuniões nacionais da ANPEd. A partir dos resultados obtidos com essa busca, recorremos a mais uma busca, agora no Google, como será justificado mais adiante, com os mesmos descritores.

\section{Mulheres refugiadas com deficiência pela Análise Omnilética: interseccionalidade silenciada}

Ao usarmos os descritores gênero, deficiência, refugiados com as variantes mencionadas na consulta à Revista Brasileira de Educação e às publicações dos GTs 15 (Educação Especial), GT 21 (Educação e Relações Étnico-Raciais) e GT 23 (Gênero, Sexualidade e Educação) nas reuniões nacionais da ANPEd, não identificamos nenhum artigo que interseccionalizasse mulheres refugiadas com deficiência.

Ainda assim, um artigo (ALEXANDRE, 2017) nos chamou a atenção por investigar o processo de inserção das crianças haitianas nas instituições educacionais de Sinop/MT, e analisar como as escolas recebem e percebem as crianças. Os dados da pesquisa revelam que nas escolas de Educação Infantil algumas crianças haitianas foram rejeitadas e discriminadas racialmente. Por terem dificuldades de falar português, elas são excluídas de algumas atividades e eventos escolares; a dificuldade de ser estrangeiro se torna um problema das crianças haitianas, e não da escola.

No caso em questão, a barreira linguística se torna uma deficiência cultural. A interseccionalidade focada no estudo está circunscrita às categorias de raça/cor, de 
http://dx.doi.org/10.5902/1984686X67656

nacionalidade e de classe. De acordo com o autor (2017, p. 15), "ser negra e ter cabelos crespos faz com que as crianças haitianas sejam percebidas como feias, sujas, exóticas e, portanto, sofrerem todos os estigmas e estereótipos que são atribuídos aos negros no Brasil".

E qual a percepção de ser mulher refugiada com deficiência? Como dissemos, não identificamos nenhum estudo ou pesquisa que nos trouxesse essa questão, que certamente precisa ser desvelada. Tendo em vista esta ausência, decidimos lançar os descritores na ferramenta de busca do Google, também na busca por produções dos últimos cinco anos. Mais uma vez, nada obtivemos contendo os três cruzamentos juntos, mas outro trabalho nos chamou a atenção.

Trata-se do artigo de Nogueira (2017), que denuncia que pessoas com deficiência refugiadas têm sido um problema invisível para as políticas públicas brasileiras. "As pessoas com deficiência constituem um grupo invisível neste debate e se tornam mais vulneráveis no atual contexto mundial, cada vez mais inquinado pela xenofobia, alimentada pela grave crise econômica dos últimos anos." Neste contexto, o autor indica que a hipótese principal é que, pessoas com deficiência, apesar de constituírem o grupo mais vulnerável dentro da população refugiada, são invisíveis aos formuladores de políticas públicas, sendo atendidos de forma reativa, por políticas formuladas para outros públicos (NOGUEIRA, 2017, p. 3).

O silêncio em relação à temática interseccional está presente até mesmo no Guia de Atendimento aos Migrantes, Refugiados, Vítimas de Tráfico de Pessoas e Brasileiros Retornados, em situação de vulnerabilidade e em áreas de fronteira (BIROL, 2016, p. 17), em que o termo deficiência é citado apenas para definir o conceito de vulnerabilidade pessoal como condição "relacionada às características individuais de determinada pessoa, podendo ser, por exemplo, o próprio sexo, a identidade de gênero, a orientação sexual, a idade, a etnia, ou uma deficiência mental ou física, dentre outros." No documento, as vulnerabilidades identitárias não são interseccionadas de modo a analisar a potencialização das barreiras quando caraterísticas individuais são sobrepostas.

De modo similar, no Relatório Anual sobre Imigração e Refúgio no Brasil (CAVALCANTI, OLIVEIRA e MACEDO, 2020), não há menção à questão da deficiência. Todavia, o documento discute a imigração no Brasil pela ótica do gênero.

As limitações na capacidade de garantir a obtenção de dados precisos sobre sexo, idade e outros dados sobre as pessoas refugiadas, demostram a existência de desafios 
metodológicos em termos de abordagem dos tamanhos das amostras, com especial atenção para os grupos de pessoas mais marginalizadas, tais como menores desacompanhados ou refugiados com deficiência, para os quais quase não há informação disponível (OECD, 2018).

Todos esses aspectos nos apontam para a ausência de uma cultura acadêmica (uma totalidade) voltada para o cruzamento destes três marcadores, juntos, como objeto de pesquisa. Isso parece ficar respaldado pelo fato de que as leis brasileiras (políticas) que atentam (práticas) para refugiados, mulheres e pessoas com deficiência - e outros grupos - o fazem, em geral, separadamente. Acresça-se a isso a jogada política (em si mesma outra totalidade) de diminuição do financiamento de pesquisas em Ciências Humanas e Sociais ${ }^{4}$, como se pôde ver nos Editais de fomento à pesquisa das principais agências governamentais ao longo de 2020 e $2021^{5}$ (sem mencionar seu próprio desmantelamento, e eis aí mais uma totalidade, como parte das atuais políticas do governo Bolsonaro - este, outra totalidade).

Por outro lado, apesar desta colisão, sabemos que há práticas sociais que vão no sentido da proteção (culturas) mínima dos direitos sociais (políticas) destes três grupos ${ }^{6}$ (que, interseccionados, tornam-se um - relação dialética e complexa), ainda que em separado, na maioria das vezes. Mesmo assim, tais práticas entram em oposição (relação dialética) com uma agenda oculta (aspecto da ordem da cultura e política) do atual (des)governo brasileiro (política), ao que tudo indica (GRILLO e TRINDADE, 2020).

Ao mesmo tempo em que estas colisões/oposições indicam contradições, a coexistência dos movimentos culturais, políticos e práticos identificados e seus contramovimentos, como nos propõe a perspectiva omnilética, dão pistas do quão incerto pode ser o daqui a pouco (complexidade), posto que, pelo próprio cenário local e global da atualidade, as incertezas são tantas (mais guerras ou pandemias surgirão? Novos "talibãs" emergirão? Seremos os mesmos no pós-pandemia? Com as crises hídrica, climática, econômica e ambiental que assolam o Brasil e o mundo no momento, sobreviveremos? Etc etc.) que, na prática, literalmente, tudo pode acontecer - de bom e de ruim. Resta-nos navegar neste mar, na esperança de que essas mesmas incertezas nos apontem caminhos de criação, em detrimento de mais destruição... 


\title{
Mulheres refugiadas com deficiência: interseccionalidade a ser desvelada no campo da educação e no contexto da inclusão
}

Vivemos uma crise humanitária, resultado de guerras, perseguições políticas e religiosas, deslocamentos em decorrência de condições ambientais e climáticas. E, no entanto, a realidade enfrentada pelas mulheres refugiadas com deficiência ainda não é conhecida e investigada.

Com base na ausência de dados e nosso olhar omnilético, somos impelidas a pensar em diversas hipóteses, que podem nos remeter a um passado de exclusão e segregação. Uma delas se apoia no fato de que, no passado, pessoas com deficiência eram eliminadas e excluídas de qualquer possibilidade de participação no contexto social. A ausência de estudos é uma forma de eliminação e de exclusão. Para existir, precisamos ser visibilizadas. No contexto atual, algumas práticas culturais vitimizam pessoas por conta de gênero e condição de diferença em relação aos padrões elencados como critério de normalidade, segundo Martuscelli (2017, p. 247):

\begin{abstract}
as meninas tendem a ser preferidas como escravas sexuais por serem consideradas virgens e possuírem menos riscos de estarem infectadas com doenças sexualmente transmissíveis. Outros casos que podem motivar o deslocamento de crianças envolvem mutilação genital de meninas e a existência de crianças albinas em locais em que partes dos corpos de albinos são usadas para rituais e feitiçarias. Essas são apenas algumas situações em que o fato de ser criança e pertencer a esse grupo social específico leva a uma perseguição.
\end{abstract}

A recente crise envolvendo a retomada do Afeganistão pelo regime Talibã, denota a vulnerabilidade das mulheres perante um grupo que as consideram desprovidas de direitos e compactuam para garantir sua invisibilidade e impedir sua participação e representatividade na sociedade (ACNUR, 2021; ESPINOSA e RIVAS, 2021; CORREIO BRAZILIENSE, 2021). Os noticiários têm mostrado a população afegã buscando sair do país em desespero, mas, pouco sabemos sobre a condição das mulheres afegãs com deficiência, que no contexto dessa situação em especial e das demais crises mundiais, historicamente enfrentam mais barreiras para conseguir emigrar e se refugiar em outros países, que possam lhes possibilitar melhores condições de vida e dignidade (SOUZA, 2017).

Compreendemos que a ausência de estudos e dados sobre a situação das mulheres refugiadas com deficiência é mais uma forma de eliminação e de exclusão, pois para existir é preciso ser visibilizada. Nesse contexto, salientamos a importância de estudos que 
http://dx.doi.org/10.5902/1984686X67656

focalizem na problemática interseccional que une deficiencidade, mulheridade $e$ refugiaridade.

A compreensão de que o processo de inclusão em educação é um aspecto da inclusão social, nos remete a pensar sobre a urgência da construção de políticas de acolhimento e atenção no âmbito nacional, focadas em grupos que necessitam de afirmação e garantia de direitos, como é o caso de mulheres refugiadas com deficiência.

A política migratória atual do Brasil ainda é orientada por duas leis básicas: o Estatuto do estrangeiro (Lei 6.815/1980), regulamentada pelo Decreto 86.715/1981, e o Estatuto dos refugiados (Lei 9.474/1997). De acordo com Borges e Brasil (2017), faz-se necessário a criação dos Comitês Estaduais para a construção de políticas públicas migratórias, pautada em uma gramática dos direitos humanos. Nas suas palavras:

pensar uma política pública de migração vai além da constituição de um quadro de agentes responsáveis e de mecanismos eficazes de recepção, acolhida, averiguação e análise dos motivos que levam a pessoa estrangeira ou apátrida a solicitar o ingresso no território brasileiro. Importa também criar as condições de possibilidade para essa pessoa se integrar (p. 233).

Grosso modo, integrar representa aprender o idioma e a cultura da pátria receptora, mas o que significa o processo de inclusão de mulheres refugiadas com deficiência, foco de nossa atual análise? Trata-se de um processo que implica intersetorialidade entre saúde, educação, assistência social, trabalho, entre outros setores que garantam possibilidades de inserção na comunidade local, possibilidade de moradia, alimentação, educação, empregabilidade. Enfim, falamos de garantias expressas na Declaração dos Direitos Humanos, que possui caráter universal, imprescindíveis no caso de grupos como o abordado neste artigo que merecem especial atenção, por conta de seu caráter interseccional ser lamentável e cinicamente utilizado pelas sociedades como desculpa e justificativa para fomentar processos de exclusão e ampliação de desigualdades.

\section{Considerações provisoriamente finais}

Buscamos discutir a interseccionalidade da mulher refugiada com deficiência sob a luz da omnilética e percebemos o silêncio que atravessa esse grupo, que concentra três características socialmente utilizadas para reforçar processos de discriminação e invisibilidade social.

A ausência de culturas, políticas e práticas voltadas para a proteção e inclusão desse grupo, nos transmite a dimensão dialética e complexa de características coexistentes, que 
http://dx.doi.org/10.5902/1984686X67656

intensificam as desigualdades sociais e comprometem sua sobrevivência. O que fazer diante da barbárie que invisibiliza o grupo em análise?

A ausência de dados, estudos, ações e estratégias para proteger e garantir a sobrevivência deste e de outros grupos, em um contexto de análise (em nosso caso, a omnilética) que evidencie as diversas facetas com base nas quais, cinicamente, as sociedades forjam as piores exclusões, traduz uma crise humanitária que precisa ser investigada e, sobretudo, combatida e eliminada.

Superamos o processo de exclusão e segregação que vitimizou milhares de pessoas ao longo da história? Não. O paradigma da inclusão é uma realidade? Somente se entendermos inclusão como processo, nunca como estado final ao qual um dia poderemos chegar, já que vivemos em um contexto mundial que se afirma pelas crises e se alimenta das desigualdades.

A omnilética propõe um olhar que tensiona processos de inclusão/exclusão, que interagem em uma complexa e dialética realidade, que nos certifica de que, diante de processos históricos marcados pela coexistência de diferentes paradigmas, não há certezas de que a existência de declarações e políticas internacionais e nacionais, garantam direitos de forma plena e/ou consolidada: tudo é um processo em constante (re) construção.

Para efeito de conclusão (sempre provisória), revelamos que neste estudo traçamos um roteiro baseado na ausência de estudos e dados, que de forma omnilética se transformaram em evidências para apresentar a necessidade de criar possibilidades de conhecer a história, ainda invisibilizada, das mulheres refugiadas com deficiência e, juntos a elas, criar condições de participação, mudança e intervenção no mundo, como nos indicava o mestre Freire (2004), em sua obra que traçou pressupostos para uma pedagogia da autonomia.

\section{Referências}

ALEXANDRE, Ivone Jesus. "Aquela preta não é minha amiga!": Interações e socialização de crianças haitianas nas escolas de educação infantil em SINOP/MT. 38우 Reunião Nacional ANPEd. GT21 - Educação e Relações Étnico-Raciais. São Luís-MA, 2017.

ANDRADE, Rodrigo de Oliveira. Ciência à míngua: sucessivos cortes no orçamento fragilizam a capacidade de financiamento à pesquisa no Brasil. Pesquisa Fapesp, São Paulo, 05 de julho de 2021. Disponível em: https://revistapesquisa.fapesp.br/ciencia-amingua/. Acesso em: 04 de dezembro de 2021. 
http://dx.doi.org/10.5902/1984686X67656

BABBIE, E. The practice of social research. 4th ed. Belmont, 1986.

BIROL, Alline Pedra Jorge. Guia de Atendimento aos Migrantes, Refugiados, Vítimas de Tráfico de Pessoas e Brasileiros Retornados, em situação de vulnerabilidade e em áreas de fronteira. Brasília: ICMPD (International Centre for Migration Policy Development) \& Ministério da Justiça e Cidadania, 2016.

BOOTH, Tony; AINSCOW, Mel. The Index for Inclusion: developing learning and participation in schools. Bristol: CSIE, 2011.

BORGES, Rosa Maria Zaia; BRASIL, Paula Zambeli Salgado. A (in)articulação governamental nas políticas públicas migratórias: os comitês estaduais de atenção a refugiados e seu papel como agente de consolidação de um sistema migratório no Brasil. In: Direitos humanos e vulnerabilidade em políticas públicas [e-book]. JUBILUT, Liliana Lyra; FRINHANI, Fernanda de Magalhães Dias; LOPES, Rachel de Oliveira (Organizadoras). Santos, SP: Editora Universitária Leopoldianum, 2017.

BRASIL. Portaria № 1.245, de 24 de março de 2020. Define, no âmbito do Ministério da Ciência, Tecnologia, Inovações e Comunicações (MCTIC), as prioridades a serem adotadas para enfrentamento do Coronavírus - Covid-19. Diário Oficial da União: seção 1-Extra, Brasília, DF, ano 158, n. 58-B, p. 1, 25 mar. 2020.

BROWNE, Sophie. Making the SDGs count for women and girls with disabilities. New York: UN Women, 2017. Disponível em: https://www.unwomen.org/en/digitallibrary/publications/2017/6/issue-brief-making-the-sdgs-count-for-women-and-girls-withdisabilities. Acesso em: 23 de maio de 2021.

CAVALCANTI, L; OLIVEIRA, T.; MACEDO, M. Imigração e Refúgio no Brasil. Relatório Anual 2020. Série Migrações. Observatório das Migrações Internacionais; Ministério da Justiça e Segurança Pública/ Conselho Nacional de Imigração e Coordenação Geral de Imigração Laboral. Brasília, DF: OBMigra, 2020.

MULHERES AFEGÃS INDIGNADAS POR RESTRIÇÕES IMPOSTAS PELO TALIBÃ. Correio Braziliense, Brasília, 20 de setembro de 2021. Disponível:

https://www.correiobraziliense.com.br/mundo/2021/09/4950469-mulheres-afegasindignadas-por-restricoes-impostas-pelo-taliba.html Acesso em: 12 de nov de 21.

ELIAS, Juliana. Mulheres ganham 19\% menos que homens -no topo, a diferença é de mais de $30 \%$. CNN Brasil, 2021. Disponível em:

https://www.cnnbrasil.com.br/business/mulheres-ganham-19-menos-que-homens-no-topodiferenca-e-de-mais-de-30/. Acesso em: 02 de junho de 2021.

ESPINOSA, Ángeles; RIVAS, Jon. A encruzilhada de duas atletas afegãs acossadas pelo Talibã. El País. Cabul e Bilbao, 02 de outubro de 2021. Disponível em:

https://brasil.elpais.com/esportes/2021-10-02/a-encruzilhada-de-duas-atletas-afegas.html Acesso em: 12 de nov de 21.

FREIRE, Paulo. Pedagogia da autonomia: saberes necessários à prática educativa. São Paulo: Paz e Terra, 2004 
GRILLO, Marco e TRINDADE, Conselheiro ataca presidente da Comissão de Ética da Presidência e diz que órgão tem 'agenda oculta'. O Globo, Rio de Janeiro, 01 de maio de 2020. Disponível em: https://oglobo.globo.com/politica/conselheiro-ataca-presidente-dacomissao-de-etica-da-presidencia-diz-que-orgao-tem-agenda-oculta-1-24406931. Acesso em: 04 de dezembro de 2021.

LUKÁCS, Gyorgy. The Young Hegel. Londres: Merlin, 1975.

MANTOO, Shabia.Conflito do Afeganistão é o que mais afeta mulheres e crianças deslocadas. ACNUR. Genebra, 13 de agosto de 2021. Disponível em: https://www.acnur.org/portugues/2021/08/13/conflito-do-afeganistao-e-o-que-mais-afetamulheres-e-criancas-deslocadas/ Acesso em: 12 de nov de 21.

MARTINAZZO, Celso José; DRESC, Óberson Isac. A compreensão do princípio da incerteza e suas implicações no processo de educação escolar. Impulso, Piracicaba, 23(58). out.dez. 2013

MARTUSCELLI, Patrícia Nabuco. Há políticas públicas para crianças refugiadas no Brasil? In: Direitos humanos e vulnerabilidade em políticas públicas [e-book]. JUBILUT, Liliana Lyra; FRINHANI, Fernanda de Magalhães Dias; LOPES, Rachel de Oliveira (Organizadoras). Santos, SP: Editora Universitária Leopoldianum, 2017.

MORIN, Edgar; LE MOIGNE, Jean Louis. A inteligência da complexidade. São Paulo: Peiropolis, 2000.

NICOLAU, Stella Maris; SCHRAIBER, Lilia Blima; AYRES, José Ricardo de Carvalho Mesquita. Mulheres com deficiência e sua dupla vulnerabilidade: contribuições para a construção da integralidade em saúde. Ciênc. saúde coletiva 18(3). Mar. 2013. Disponível em: https://www.scielo.br/j/csc/a/x4Ct7sJ4krY7wzGH5XX57nR/?lang=pt . Acesso em: 05 de agosto de 2021.

NOGUEIRA, Ary Jorge Aguiar. Pessoas com deficiência refugiadas: um problema invisível. 6ำ Encontro ABRI - Associação Brasileira De Relações Internacionais. 25 a 28 de julho de 2017 - Campus Coração Eucarístico da PUC Minas, Belo Horizonte- MG. Disponível em:

http://www.encontro2017.abri.org.br/resources/anais/8/1498072146_ARQUIVO_Pessoasc omdeficienciarefugiadas-AryJorgeAguiarNogueira-6encontroABRI.pdf. Acesso em: 20 de julho de 2021.

NOVAES, Lucas. Com deficiência e empoderadas: Mulheres refugiadas e migrantes recebem capacitação para o mercado de trabalho no Brasil. ACNUR/BRASIL, 2000. Disponível em https://www.acnur.org/portugues/2020/12/03/com-deficiencia-eempoderadas-mulheres-refugiadas-e-migrantes-recebem-capacitacao-para-o-mercadode-trabalho-no-brasil/. Acesso em: 20 de julho de 2021.

ORGANIZATION FOR THE ECONOMIC COOPERATION AND DEVELOPMENT (OECD). Learning from Data: Proceedings from the Third Policy Forum. Strength through Diversity, 2018. Disponível em http://www.oecd.org/education/school/3rd-ForumProceedings.pdf. Acesso em: 05 de agosto de 2021. 
ORGANIZAÇÃO DAS NAÇÕES UNIDAS (ONU). Políticas para pessoas com deficiência são cruciais para ODSs. Nova Yorque: ONU, 2016. 123p. Disponível em https://news.un.org/pt/audio/2016/12/1191741 2/2. Acesso em: 12 de maio de 21.

PRADO, Marco Aurélio Máximo e ARAUJO, Suzana Almeida. Políticas de atendimento a migrantes e refugiados no Brasil e aproximações da psicologia. Rev. psicol. polít. [online]. 2019, vol.19, n.46, pp. 570-583.

SALDAÑA, Paulo. Em meio a pandemia, governo Bolsonaro investe contra pesquisa em ciências humanas. Folha de São Paulo, São Paulo, 26 de março de 2020. Disponível em: https://www1.folha.uol.com.br/educacao/2020/03/em-meio-a-pandemia-governobolsonaro-investe-contra-pesquisa-em-ciencias-humanas.shtml?origin=folha. Acesso em: 04 de dezembro de 2021.

SANTOS, Mônica Pereira dos. Políticas Públicas de Inclusão de Pessoas com Deficiência: uma análise omnilética. In: Políticas educacionais e impactos na escola e na sala de aula [e-book]. ALMEIDA, Maria Isabel de, et al (Organizadores). Araraquara, SP: Junqueira\&Marin, 2012. p. 1223-1234.

SANTOS, Mônica Pereira dos. Dialogando sobre Inclusão em Educação: contando casos (e descasos). Curitiba: CRV, 2013.

SILVA, G. J; CAVALCANTI, L; OLIVEIRA, T; MACEDO, M. Refúgio em Números, 5aㅡ. Ed. Observatório das Migrações Internacionais; Ministério da Justiça e Segurança Pública/Comitê Nacional para os Refugiados. Brasília, DF: OBMigra, 2020.

SOUZA, Ana Clara Telles Cavalcante de. Sob o véu da intervenção: discursos de gênero na guerra do Afeganistão. Revista Estudos Feministas [online]. 2017, v. 25, n. 3], pp. 1297-1312. Disponível em:

https://www.scielo.br/j/ref/a/qnhcNkQFhJQm683sSmb7TBg/abstract/?lang=pt.. Acesso em 9 de Dezembro de 2021.

UNITED NATIONS EDUCATIONAL AND SCIENTIFIC COOPERATION (UNESCO). Relatório de Ciências da Unesco. Paris: ONU, 2021, 74p. Disponível em: https://unesdoc.unesco.org/ark:/48223/pf0000377250_por. Acesso em: 04 de dezembro de 2021.

UNITED NATIONS HIGH COMMISSIONER FOR REFUGEES (UNHCR). Tendências Globais de Deslocamento Forçado em 2019. Copenhagen: ONU, 2020. 84p. Disponível em: https://www.unhcr.org/refugee-statistics/. Acesso em: 12 de maio de 21.

UNITED NATIONS EDUCATIONAL AND SCIENTIFIC COOPERATION (UNESCO). Declaração mundial sobre educação para todos e plano de ação para satisfazer as necessidades básicas de aprendizagem. Jomtien, Tailândia: UNESCO, 1990. Disponível em http://unesdoc.unesco.org/ images/0008/000862/086291 por.pdf. Acesso em 20 de maio de 2019.

UNITED NATIONS EDUCATIONAL AND SCIENTIFIC COOPERATION (UNESCO). Educação para todos: o compromisso de Dakar. Dakar, Senegal: UNESCO, 2000. 
http://dx.doi.org/10.5902/1984686X67656

\section{UNITED NATIONS EDUCATIONAL AND SCIENTIFIC COOPERATION (UNESCO). Marco da educação 2030: Declaração de Incheon. Incheon, Coréia do Sul: UNESCO, 2015.}

\section{Notas}

${ }^{1}$ Registramos aqui nosso agradecimento especial ao CNPq, que nos apoia com bolsa de produtividade e financiamento para pesquisa.

${ }^{2}$ Segundo o Instituto Brasileiro de Geografia Estatística - IBGE, no Brasil, as meninas e mulheres possuem nível educacional mais alto e estudam mais anos em média do que os homens (Fonte: https://educa.ibge.gov.br/jovens/materias-especiais/materias-especiais/20453-estatisticas-de-generoindicadores-sociais-das-mulheres-no-brasil.html). Acesso em: 10 de agosto de 2021.

${ }^{3} \mathrm{https}: / / w w w . a c n u r . o r g / p o r t u g u e s /$

${ }^{4}$ Por exemplo, Saldaña (2020) e Andrade (2021) deixam muito claro o quanto os sucessivos cortes orçamentários têm fragilizado a capacidade de financiamento à pesquisa no Brasil. Vale a pena ler, a este respeito, o recente Relatório de Ciências emitido pela UNESCO (2021) que aponta dados precisos que mostram o recrudescimento do financiamento das pesquisas em Humanas mundo afora e no Brasil, o que tem privilegiado as chamadas ciências "duras" e as áreas tecnológicas. Prova cabal encontra-se na Portaria № 1.245, de 24 de março de 2020, que define, no âmbito do Ministério da Ciência, Tecnologia, Inovações e Comunicações (MCTIC), as prioridades a serem adotadas para enfrentamento do Coronavírus - Covid-19, excluindo, quase que integralmente, as áreas Humanas.

5 Basta uma breve consulta aos sites da CAPES (https://www.gov.br/capes/pt-br) e do CNPq (https://www.gov.br/cnpq/pt-br) para confirmar.

${ }^{6}$ Referimo-nos, genericamente, aos trabalhos sociais desenvolvidos por Movimentos Sociais e Organizações Não-governamentais e eles associadas, ou independentes. 